sclerosis in Rochester, Minn. A 60-year appraisal. Arch Neurol 1971; 25:105-11.

${ }^{11}$ Millar JHD. Multiple sclerosis, a disease acquired in childhood. Springfield: Charles C Thomas, 1971.

12 Shepherd DI, Downie AW. Prevalence of multiple sclerosis in north-east Scotland. Br Med f 1978;ii:314-6.

13 Shepherd DI, Downie AW. A further prevalence study of multiple sclerosis in north-east Scotland. F Neurol Neurosurg Psychiatry 1980; 43:310-5.

14 Dean G, Kurtzke JF. On the risk of multiple sclerosis according to age at immigration to South Africa. $\mathrm{Br} \mathrm{MedF} 1971$; iii:725-9.

15 Alter M, Leibowitz U, Speer J. Risk of multiple sclerosis related to age at immigration to Israel. Arch Neurol 1966;15:234-7.

16 Poskanzer DC, Schapira K, Miller H. Multiple sclerosis and poliomyelitis. Lancet 1963;ii:917-21.

17 Kurtzke JF, Hyllested K. Multiple sclerosis in the Faroe Islands: I. Clinical and epidemiological features. Ann Neurol 1978;v:6-21.

18 Anonymous. Histocompatibility antigens and multiple sclerosis. Lancet $1976 ; \mathrm{ii}: 1286-7$

19 Anonymous. HLA and disease 1980. Br Med f 1980;280:1485-6.

${ }^{20}$ Kuroiwa Y, Okihiro MM. Multiple sclerosis in Hawaii, a preliminary report. Hawaii Med f $1969 ; 28: 374-6$.

${ }^{21}$ Dean G, Grimaldi G, Kelly R, Karhausen L. Multiple sclerosis in southern Europe. I: Prevalence in Sicily in 1965. F Epidemiol Community Health 1979;33:107-10.

22 Vassallo L, Elian M, Dean G. Multiple sclerosis in southern Europe. II : Prevalence in Malta in 1978. F Epidemiol Community Health 1979;33 111-3.

\section{Angiosarcoma of the liver: A growing problem?}

Angiosarcoma of the liver, otherwise called Kupffer-cell sarcoma or malignant haemangioendothelioma, is rare: fewer than 200 such tumours have been reported world wide. It usually occurs in the sixth and seventh decades and is more common in men than in women. Angiosarcoma is often multifocal, arising in a scarred or cirrhotic liver, and consists of malignant endothelial cells supported on a reticulin framework. In some areas tumour cells make a homogeneous tumour, while in others the hepatic cell plate structure is still present, though compressed, and dilated sinusoids are lined by malignant endothelial cells. ${ }^{1}$

Angiosarcoma is one of the cancers with an identified cause: thorotrast, arsenic, and vinylchloride have all been clearly implicated. Thorotrast, a colloidal preparation of thorium dioxide, was used as a radio-opaque contrast medium between 1928 and the mid-1950s. ${ }^{2}$ When given intravenously more than $70 \%$ of the dose is taken up by the liver, and the mean radiation dose received by the liver varies between 1000 and 3500 rads. Tumours appear 12 years or more after exposure, and in a review of 123 thorotrast-induced tumours ${ }^{3}$ there were 41 angiosarcomas, 40 cholangiocarcinomas, 24 hepatocellular carcinomas, and 18 other carcinomas. Though thorotrast has not been used for about 25 years, new cases are still appearing. The peak incidence may now be passed, ${ }^{4}$ but a sizeable population of recipients are still alive, and their accumulated radiation dose from retained thorotrast is still increasing. Chronic arsenical intoxication has long been recognised as a cause of liver fibrosis, cirrhosis, and angiosarcoma. It was an occupational disease among vintners in Moselle ${ }^{5}$ and was seen in patients given prolonged treatment with Fowler's solution or potassium arsenite. ${ }^{6}$ In Britain the use of arsenic in pesticides has diminished considerably since 1960 and the use of arsenical drugs was largely discontinued after 1950 .

Polyvinylchloride is formed by polymerisation of liquid vinylchloride monomer. Commercial production began in the 1940s, and the industry has grown prodigiously; current
British production is around 400000 tons per annum. Polyvinylchloride is used in a mass of different products, ranging from piping to credit cards. Monomer can leak out of polyvinylchloride in tiny amounts, and, while this probably poses no threat to the general public, last year the United States Food and Agriculture Administration banned the use of polyvinylchloride in food containers. The main risk, however, lies with the workers in the manufacturing industry, and was very high in those cleaning the autoclaves, who were exposed to concentrations of monomer fumes as high as $10000 \mathrm{ppm}$. Liver disease and acro-osteolysis (thinning of the bones in the hands and feet) were first noted in Russia and Eastern Europe in the 1950s and 1960s, some time before similar observations were made in Western Europe and North America. The oncogenic potential of vinylchloride was first shown in studies in animals in $1971,{ }^{7}$ and subsequent work showed that exposure of rats to $50 \mathrm{ppm}$ for four hours daily five days a week for one year was sufficient to induce tumours. ${ }^{8}$ The first human case of angiosarcoma was reported in the vinylchloride industry in $1974 .^{9}$ Since then safety regulations have been progressively tightened, so that the maximum permissible eight-hour average is now $10 \mathrm{ppm}$ with a ceiling of $30 \mathrm{ppm}$. The latent interval between first exposure and diagnosis of the tumour lies between 12 and 29 years, and-as with the recipients of thorotrast-more cases seem likely to come to light with time.

Most patients with angiosarcoma of the liver present with abdominal pain and swelling with loss of weight. ${ }^{10}$ Enlargement of the liver is almost invariable, and ascites is common; the ascitic fluid is often bloodstained. Patients exposed to vinylchloride may also have acro-osteolysis. Laboratory findings are non-specific, but thrombocytopenia is common and microangiopathic haemolytic anaemia and consumption coagulopathy have been reported. ${ }^{2}$ The prognosis is grim: 22 of 55 patients died within three months, and all were dead within one year. ${ }^{1}$ The only hope of cure lies in transplantation or resection, but the latter is seldom possible since the tumour is usually widespread in both lobes and there is often underlying cirrhosis.

What is the size of the problem in Britain? A register of cases was set up in 1974, and the second report has just been published. ${ }^{11}$ Between 1963 and 1977 a total of 35 cases were found acceptable to the panel of histopathologists, and the number of cases seen annually has risen in the last two years. A known cause or agent was identified in only 10 cases-eight due to thorotrast and two to vinylchloride. There was possible exposure to vinylchloride in four other cases, and the survey also suggested an excess of cases in the electrical industry. How many patients will develop angiosarcoma over the next two decades due to prior exposure to thorotrast or vinylchloride is unknown. Nevertheless, doctors should be alert to this possible diagnosis in those with the appropriate history.

${ }^{1}$ Ishak K. Mesenchymal tumours of the liver. In: Okuda K, Peters RL, eds. Hepatocellular carcinoma. New York: Wiley Medical, 1976:247-307.

2 Battifora HA. Thorotrast and tumours of the liver. In: Okuda K, Peters RL, eds. Hepatocellular carcinoma. New York: Wiley Medical, 1976: 83-93.

${ }^{3}$ Smorcn GL, Battifora HA. Thorotrast-induced hepatoma. Cancer 1972; $30: 1252-9$.

${ }^{4}$ Faber M. Twenty-eight years of continuous follow-up of patients injected with thorotrast for cerebral angiography. Environ Res 1979;18:37-43.

${ }^{5}$ Roth F. The sequelae of chronic arsenic poisoning in Moselle vintners. German Medical Monthly 1957;2:172-5.

${ }^{6}$ Regelson W, Kim U, Ospina J, Holland JF. Hemangioendothelial sarcoma of liver from chronic arsenic intoxication by Fowler's solution. Cancer $1968 ; 21: 514-22$.

7 Viola PL, Bigotti A, Caputo A. Oncogenic response of rat skin, lungs, and bones to vinylchloride. Cancer Res 1971 ;31:516-22.

${ }^{8}$ Anonymous. More facts on vinylchloride and cancer. $\mathrm{Br}$ Med $\mathcal{F} 1974$;iv: 486-7. 
9 Creech JL, Johnson MN. Angiosarcoma of liver in the manufacture of polyvinylchloride. Fournal of Occupational Medicine 1974;16:150-1.

11 Makk L, Delmore F, Creech JL, ot al. Clinical and morphologic features of hepatic angiosarcoma in vinvlchloride workers. Cancer 1976;37 $1.9-63$.

11 Baxter PJ, Anthony PP, Macsween RNM, Scheuer PJ. Angiosarcoma of the liver: annual occurrence and actiology in Great Britain. Br. F Ind Med $1980 ; \mathbf{3 7}: 213-21$

\section{Drugs for breast pain}

Traditionally breast pain is regarded as a trivial symptom in most women and occurs in severe form only in "neurotic" patients. This negative attitude has prevented proper study of the problem for many years, but recent advances in two areas have rekindled interest. Firstly, careful clinical study has shown that "ncuroticism" is not a major factor, " and that several patterns of breast pain may be distinguished from the clinical history." Secondly, the introduction of antihormone drugs acting on specific areas of the pituitary-ovarian axis has increased the range of possible approaches to treatment. Drug treatment is likely to be preferable to the radical alternativesubcutaneous mastectomy and implant-an operation which has uncertain indications and long-term problems from capsular fibrosis.

Some widely used drug treatments should, however, be discarded. Diuretics have often been used to counteract supposed water retention, but isotopic measurements of changes in total body water showed no differences between controls and patients with breast pain. ${ }^{3}$ Another popular hypothesis, inadequate function of the corpus luteum, has been strongly supported by Mauvais-Jarvis and his colleagues in France, ' based on the results of radioimmunoassay studies showing low luteal-phase progesterone values. This group report good results in uncontrolled studies with lynoestrenol, a synthetic progestogen, but a British double-blind study showed that another progestogen, dydrogesterone, was no better than placebo for tenderness of the breasts. ${ }^{5}$

Two more durable theories, hyperprolactinaemia and oestrogenic overstimulation, have given the impetus to the investigation of the newer drugs bromocriptine and danazol. Bromocriptine is an ergot derivative which acts as a dopamine agonist and lowers the serum prolactin concentration, while danazol is a synthetic derivative of ethisterone and acts by suppressing ovarian function.

Bromocriptine was first used for the treatment of prolactinomas, but several reports ${ }^{6-8}$ of its success in treating breast pain have confirmed the first report by Schulz and his colleagues in 1975." Taken together, these reports showed symptomatic response rates between $70 \%$ and $90 \%$ in a total of 61 patients (with normal prolactin concentrations) using $5 \cdot 0-7.5 \mathrm{mg}$ bromocriptine a day in divided doses. These studies were uncontrolled, but the results were confirmed in two double-blind studies ${ }^{10} 11$ using $2.5 \mathrm{mg}$ bromocriptine twice daily, and giving an overall response rate of around $75 \%$. The larger, Cardiff study ${ }^{11}$ showed that patients with cyclical breast tenderness and nodularity improved, while non-cyclical breast symptoms and general menstrual symptoms were unaffected. This remarkable selectivity of the drug was confirmed by the double-blind study of Andersen et al ${ }^{1: 2}$ of the premenstrual tension syndrome, where bromocriptine improved only the breast symptoms. Side effects-dizziness, nausea, and headache-were seen in about $40 \%$ of the patients, and these were severe enough to cause a drop-out rate of $17 \%$ in one trial. ${ }^{11}$ To reduce the frequency and severity of side effects most authors recommend an upper daily dose of $5 \mathrm{mg}$, and dosage should be increased gradually when starting treatment.

Danazol was first marketed for treatment of endometriosis, but in 1971 Greenblatt and his colleagues ${ }^{13}$ reported improvement of breast symptoms in women with endometriosis while taking the drug. Further reports from the same group ${ }^{1415}$ described the use of danazol in dosages from 100 to $400 \mathrm{mg}$ daily for three to six months in over 300 women with varying types of benign breast disease and reported total resolution of pain and nodularity in about $80 \%$ of patients. Tenderness responded within one month of starting treatment, whereas the regression of nodules was much slower. While these results are promising, these studies and two others from the United States ${ }^{16} 17$ were uncontrolled, and they need to be confirmed in a double-blind placebo study. The main side effects are gain in weight, amenorrhoea, headache, and acne, but these are mild or absent at the lower dosages. The only direct comparison between bromocriptine and danazol showed an identical response rate of $70 \%$ for each drug. ${ }^{7}$ Apart from the management of patients who fail to respond to these drugs two problems remain: the length of treatment and the mechanisms of action, both of which are unknown and require further study.

These new drugs offer effective treatment for many patients with severe pain in nodular breasts, and provide an alternative to the surgical approach of subcutancous mastectomy. Their use should be considered only in these severe cases, since most patients readily accept their symptoms if their fears of underlying malignancy can be allayed.

${ }^{1}$ Preece PE, Mansel RE, Hughes LE. Mastalgia: psychoneurosis or organic disease? Br Med f 1978; i:29-30.

2 Preece PE, Mansel RE, Hughes LE, Baum M, Bolton PM, Gravelle IH. Clinical syndromes of mastalgia. Lancet 1976;ii:670-3.

Preece PE, Richards AR, Owen GM, Hughes LE. Mastalgia and total body water. Br Med f 1975; iv:498-500.

4 Sitruk-Ware R, Sterkers N, Mauvais-Jarvis P. Benign breast disease I : hormonal investigation. (Obstet Gynecol 1979;53:457-60.

5 Day JB. Clinical trials in the premenstrual syndrome. Curr Med Res Opin $1979 ; 6$,suppl $5: 40-5$.

${ }^{6}$ Martin-Comin J, Pujol-Amat P, Cararach V, Davi E, Robyn C. Treatment of fibrocystic disease of the breast with a prolactin inhibitor: $2-\mathrm{Br}$ alpha-ergocryptine (CB-154). Obstet Gynecol 1976;48:703-6.

' Montgomery ACV, Palmer BV, Biswas S, Monteiro JCMP. Treatment of severe cyclical mastalgia. $\mathcal{F} R$ Soc $M e d 1979 ; 72: 489-91$.

${ }^{8}$ Mussa A, Dogliotti L. Treatment of benign breast disease with bromocriptine 7 Endocrinol Invest 1979;2:87-91.

${ }^{9}$ Schulz KD, Del Pozo E, Lose KH, Kunzig HJ, Geiger W. Successful treatment of mastodynia with the prolactin inhibitor bromocriptine (CB-154). Archiv fur Gynaekologie 1975;220:83-7.

10 Blichert-Toft $M$, Andersen AN, Henriksen OB, Mygind T. Treatment of mastalgia with bromocriptine: a double-blind cross-over study. $\mathrm{Br} \mathrm{Med}$ f $1979 ; \mathrm{i}: 237$.

11 Mansel RE, Preece PE, Hughes LE. A double-blind trial of the prolactin inhibitor bromocriptine in painful breast disease. $B r \mathcal{F}$ Surg $1978 ; 65$ : $724-7$

1: Andersen AN, Larsen JF, Steenstrup OR, Svendstrup B, Nielsen J. Effect of bromocriptine on the premenstrual syndrome. A double-blind clinical trial. Brf (Obstet Gynaecol 1977;84:370-4.

${ }^{13}$ Greenblatt RB, Dmowski WP, Mahesh VB, Scholer HFL. Clinica studies with an antigonadotrophin-danazol. Fertil Steril $1971 ; 22$ : 102-12.

1 Asch RH, Greenblatt RB. The use of an impeded androgen-danazolin the management of benign breast disorders. Am $\mathcal{F}$ Obstet Gynecol 1977;127:130-4

1.5 Nezhat C, Asch RH, Greenblatt RB. Danazol for benign breast disease. Amf ()bstet Gynecol 1980;137:604-7.

16. Baker HW, Snedecor PA. Clinical trial of danazol for benign breast disease. Am Surg 1979;45:727-9.

17 Lauersen NH, Wilson $\mathrm{KH}$. The effect of danazol in the treatment of chronic cystic mastitis. ()bstet Gynecol 1976;48:93-8. 